\title{
A model of the electrical behaviour of myelinated sensory nerve fibres based on human data
}

\author{
W. A. Wesselink J. Holsheimer H. B. K. Boom \\ Institute for Biomedical Technology, University of Twente, Enschede, The Netherlands
}

\begin{abstract}
Calculation of the response of human myelinated sensory nerve fibres to spinal cord stimulation initiated the development of a fibre model based on electrophysiological and morphometric data for human sensory nerve fibres. The model encompasses a mathematical description of the kinetics of the nodal membrane, and a non-linear fibre geometry. Fine tuning of only a few, not well-established parameters was performed by fitting the shape of a propagating action potential and its diameterdependent propagation velocity. The quantitative behaviour of this model corresponds better to experimentally determined human fibre properties than other mammalian, nonhuman models do. Typical characteristics, such as the shape of the action potential, the propagation velocity and the strength-duration behaviour show a good fit with experimental data. The introduced diameter-dependent parameters did not result in a noticeable diameter dependency of action potential duration and refractory period. The presented model provides an improved tool to analyse the electrical behaviour of human myelinated sensory nerve fibres.
\end{abstract}

Keywords-Human nerve fibre, Mathematical model, Action potential, Conduction velocity, Chronaxie

Med. Biol. Eng. Comput., 1999, 37, 228-235

\section{Introduction}

\subsection{General introduction}

THE INCREASED application of electrical stimulation to nervous tissue in clinical practice has resulted in a growing interest in the analysis and modelling of the response of neural elements to applied electrical stimuli. Electrical stimulation to regain neuromuscular control, stimulation of the auditory nerve to recover hearing and spinal cord stimulation (SCS) in the management of chronic, intractable pain are, among others, well-known applications in modern medicine. In order to predict the outcome of the underlying neurophysiological mechanisms, and to design better stimulation methods, computer modelling of the response of electrically stimulated myelinated nerve fibres is a frequently employed method.

VELTINK et al. (1989) and RATTAY and ABERHAM (1993) developed computer models to simulate the response of myelinated motor fibres to functional electrical stimulation. FRINNS and TEN KATE (1994) described in detail a model to predict the response of the auditory nerve to stimulation with cochlear implants, and they concluded that conduction properties of the nerve limit the repetitive stimulation rate. STRUIJK et al. (1992) developed a computer model to predict how myelinated sensory nerve fibres respond to electrical stimula-

Correspondence should be addressed to Dr J. Holsheimer; email: j.holsheimer@el.utwente.nl

First received 11 May 1998 and in final form 18 September 1998

(C) IFMBE: 1999 tion of the spinal cord. They showed that the excitation threshold of dorsal column fibres is substantially reduced by the presence of collateral branches.

Usually, such models consist of two submodels: a fibre model and linked to it, a volume conductor model to translate the nervous tissue properties to physiologically measurable phenomena. In the studies mentioned above, the parameters of the fibre models focused on the prediction of the electrical behaviour of human nerve fibres were based on experimental data obtained from animals: rabbit (CHIU et al., 1979), rat (SCHWARZ and EIKHOF, 1987), and toad (FRANKENHAEUSER and HUXLEY, 1964). Since the first model describing the electrical kinetics of a squid nerve membrane (HODGKIN and HUXLEY, 1952), various parameters have been used. The general framework of the fibre model involved, however, still remains, although it was shown that the mammalian nodal membrane has far less active potassium channels than, in, for example, amphibians (CHIU et al., 1979; SCHWARZ and EIKHOF, 1987).

MCNEAL (1976) calculated the response of a complete myelinated nerve fibre to an externally applied electrical field by actually combining a fibre model with a simple, homogenous volume conductor model. STRUIJK et al. (1992) presented a more elaborate McNeal-type cable model of branched myelinated nerve fibre with all nodes made excitable, and applied it in a computer model to simulate spinal cord stimulation (SCS).

There are indications that non-human fibre models give results which strongly differ from experimental human data. Computer model predicted activation thresholds exceeded measured data by a factor 2.5-3 (STRUIJK et al., 1993) with 
a fibre model based on rabbit nerve fibre parameters (CHIU et al., 1979). In addition, calculated chronaxie values are a factor 4.5 lower than the experimental data of BEMENT and RANCK (1969).

In recent years, many quantitative data on geometrical and electrical properties of human myelinated sensory nerve fibres have become available. In the current study, evaluation of a fibre model based on these new data was performed by incorporating it in a computer model that calculates the effects of electrical stimulation on sensory nerve fibres in the spinal cord. Validation of the response of both this nerve fibre model and the fibre model previously used for SCS modelling (SWEENEY et al., 1987) is performed by comparing the shape of the action potential (AP), the conduction velocity, the strength-duration properties and the refractoriness with experimental data obtained by several authors (see Table 1).

\subsection{Experimental data and relations to validate the fibre model}

We validated the new model by comparing its behaviour with experimental data for human nerve fibres. PAINTAL (1966) concluded from experiments on cats that AP duration is inversely related to fibre diameter; this, however, has not yet been confirmed for human fibres. Moreover, amplitude as well as rise time and fall time vary with temperature, but these parameters are unknown for human fibres at body temperature. Therefore, we estimated them from plots of measured human APs as presented by SCHWARZ et al. (1995) at $20^{\circ}$ and $25^{\circ} \mathrm{C}$, and used them for model validation purposes.

Conduction velocities of propagating APs in human touch afferents were determined by SCHALOW et al. (1995) and VAN VEEN et al. (1995). They showed that the ratio of the conduction velocity of an AP and the diameter of these fibres varies between $2.5 \times 10^{6} \mathrm{~s}^{-1}$ and $4.2 \times 10^{6} \mathrm{~s}^{-1}$. These ratios are substantially below the value of $5.7 \times 10^{6} \mathrm{~s}^{-1}$ previously assumed for human fibres and based on experiments on cats (BOYD and KALU, 1979).

Several papers presenting strength-duration data for nerve fibres in the central nervous system of cats (BEMENT and RANCK, 1969; JANKOWSKA and ROBERTS, 1972; WEST and WOLSTENCROFT, 1983; ISHIKAWA et al., 1996) and rats (NoWAK and BULliER, 1998) have been published. In Table 1 , the values of the experimentally determined chronaxies are summarised. Although the range is fairly wide $(50-271.5 \mu \mathrm{s})$, the reported chronaxies are all clearly higher than currently available mammalian fibre models predict, i.e. 15-45 $\mathrm{s}$ (FRIJNS et al., 1994). Moreover, WEST and WOLSTENCROFT (1983), JANKOWSKA and ROBERTS (1972) and NOWAK and BULLIER (1998) also indicated an inverse relation between chronaxie and conduction velocity, which may partly explain the wide range.

In contrast, only a few papers have reported on the strengthduration behaviour of human peripheral nerve fibres. MOGYROS et al. (1996) found a significant difference in strength-duration behaviour between motor and sensory nerve fibres in humans, the latter having chronaxie values of $665 \pm 182 \mu \mathrm{s}$. A similar difference was reported by PANIZZA et al. (1994) and BOSTOCK and ROTHWELL (1997), where sensory nerve fibres had average chronaxie values of $349 \mu \mathrm{s}$ and $535 \mu \mathrm{s}$, respectively. In the latter two studies, the method of 'latent addition' was used, which results in a strength-delay curve analogous to the strength-duration curve. To validate the method of latent addition, PANIZZA et al. (1994) also measured strength-duration curves and determined an average chronaxie of $318 \mu \mathrm{s}$, which is about $9 \%$ less. For our purpose, the usefulness of these data is somewhat limited, since in these three studies, surface stimulation and recording techniques were used, resulting in mean values related to compound action potentials of sensory nerve. Recently, PANIZZA et al. (1998) presented strength-delay curves of peripheral sensory nerve fibres obtained with microneurographic techniques, whereby an average chronaxie value of $369 \mu$ s was found. Although surface stimulation was applied, these results will probably provide a better fit to real single fibre data. The remarkable difference in strength-duration behaviour between the human and animal data may have several origins. The animal data was obtained from fibres in the central nervous system, whereas human data was retrieved from peripheral nerves. Also, surface stimulation, as used for human experiments, will probably lead to higher chronaxie values than direct fibre activation due to the relatively large distance between electrode and nerve fibre (FRIJNS et al., 1994). Finally, there could be a real difference between humans and other mammals, similar to that found for the propagation velocity.

Several authors have measured quantitatively the refractoriness of human myelinated nerve fibres. GILLIAT and WILSON (1963) found an absolute refractory period of about $0.65 \mathrm{~ms}$

Table 1 Experimentally determined characteristics of myelinated nerve fibres

\begin{tabular}{llll}
\hline Parameter & \multicolumn{1}{c}{ Value } & \multicolumn{1}{c}{ Specifications } & \multicolumn{1}{c}{ Reference } \\
\hline Rise time $[\mu \mathrm{s}]$ & 270 & $20^{\circ} \mathrm{C}$, human sens. nerve & SCHWARZ et al., 1995 \\
& 204 & $25^{\circ} \mathrm{C}$, human sens. nerve & SCHWARZ et al., 1995 \\
Fall time $[\mu \mathrm{s}]$ & 1829 & $20^{\circ} \mathrm{C}$, human sens. nerve & SCHWARZ et al., 1995 \\
& 1464 & $25^{\circ} \mathrm{C}$, human sens. nerve & SCHWARZ et al., 1995 \\
Conduction velocity/diameter $[1 / \mu \mathrm{s}]$ & $2.5-4.1$ & Human, body temperature & SCHALOW et al., 1995 \\
& $3.0-4.0$ & Human, body temperature & VAN VEEN et al., 1995 \\
Chronaxie $[\mu \mathrm{s}]$ & $70-90$ & Cat dorsal column fibres & BEMENT and RANCK 1969 \\
& $180 \pm 60$ & Cat spinal cord fibres & WEST and WOLSTENCROFT 1983 \\
& $50-100$ & Cat spinal cord fibres & ISHIKAWA et al., 1996 \\
& 271.5 & Rat small cortex fibres & NowAK and BULLIER 1998 \\
& $665 \pm 182$ & Human sens. nerve & MOGYOROS et al., 1996 \\
& 535 & Human sens. nerve & BOSTOCK and ROTHWELL 1997 \\
& 349,318 & Human sens. nerve & PANIZZA et al., 1994 \\
Absolute refractory period (ARP) [ms] & 369 & Human sens. nerve fibres & PANIZZA et al., 1998 \\
& 0.65 & Human median nerve & GILLIATT and WILLSON 1963 \\
& 0.75 & Human median nerve & BUCHTHAL and ROSENFALCK 1966 \\
& $0.58-0.79$ & Human median nerve & TACKMANN and LEHMANN 1974 \\
\hline
\end{tabular}


and a relative refractory period of $3.0 \mathrm{~ms}$ for human median nerve. BUCHTHAL and ROSENFALCK (1966) reported an absolute refractory period of $0.75 \mathrm{~ms}$ for the sensory median nerve. TACKMANN and LEHMANN (1974) measured values between 0.58 and $0.79 \mathrm{~ms}$, and found a relative refractory period of 3.5 to 5 times the absolute refractory period. Similar values were measured in cat myelinated fibres with diameters of $10-20 \mu \mathrm{m}$ (absolute refractory period $=0.5 \mathrm{~ms}$, ratio of relative refractory period and absolute refractory period $=4$ ), whereas the absolute refractory period was about 1.5 times the duration of the AP (PAINTAL, 1973).

\section{Methods}

\subsection{Parameters applied to the fibre model}

Parameters of membrane kinetics and morphometry of nerve fibres derived from measurements on human material were used to define parameters for our model. SCHWARZ et al. (1995) presented results from electrophysiological experiments on human nerve fibre membrane. They recorded sodium and potassium currents of single nodes of sensory nerve fibres under current and voltage clamp conditions at room temperature. From these recordings, they calculated the parameters required to compose a mathematical model structurally based on the Frankenhaeuser-Huxley equations (FRANKENHAEUSER and HUXLEY, 1964). In addition to a capacitive component, the current through the nodal membrane is proposed to be carried by a sodium, a (fast) potassium as well as a leakage component, although the contribution of potassium current is small. The slow potassium current was neglected, since it hardly influences fibre behaviour except for the repetitive firing rate. The sodium permeability and the potassium conductance strongly depend on the membrane potential, whereas the leakage conductance is assumed to be constant. To calculate the response of a myelinated nerve fibre to extracellular stimulation, a McNeal-type cable model with each compartment representing a node of Ranvier was applied.

The temperature-dependent parameters of the fibre model were adjusted to body temperature using the $Q_{10}$ factors presented by SCHWARZ et al. (1995). The value of a temperature-dependent parameter $X_{h}$ at a higher temperature $T_{h}$ can be derived from the value $X_{l}$ at a lower temperature $T_{l}$ according to eqn. 1 :

$$
X_{h}=X_{l} Q_{10}^{\left(T_{11}-T_{l} / 10\right)}
$$

All temperature corrections were effected using $Q_{10}$ factors given by SCHWARZ et al. (1995), except for sodium activation. The temperature dependency of sodium activation is approximately inversely proportional to the temperature dependency of the rise time of the AP. The rise time of the measured APs decreased by $24 \%$ between $20^{\circ}$ and $25^{\circ} \mathrm{C}$ (corresponding to $\mathrm{Q}_{10} \approx(1.7)^{-1}$ ). Therefore, we used a $\mathrm{Q}_{10}$ of 1.7 (instead of 2.1 ) for sodium activation, resulting in a $30 \%$ lower sodium activation at body temperature. In addition to a better fit with the rise time of the measured $\mathrm{AP}$ at $25^{\circ} \mathrm{C}$, the application of a lower $Q_{10}$ also resulted in a monotonously increasing rising phase of the propagating $A P$ at $37^{\circ} \mathrm{C}$, whereas the $Q_{10}$ value proposed by SCHWARZ et al. (1995) resulted in a double peak in the rising phase of the propagating AP.

Unfortunately, data concerning the dimensions of the fibres as used by SCHWARZ et al. (1995) are lacking. Morphometric data of human sensory nerve fibres concerning the myelin sheath thickness and intemodal distance were published by BEHSE (1990). After correction for $17 \%$ shrinkage of the myelin sheath and the axon, a linear relation seems to be valid between axon diameter and fibre diameter for fibre diameters larger than $2.4 \mu \mathrm{m}$ :

$$
d=C_{d} D-D_{d}
$$

$D$ being fibre diameter and $d$ axon diameter; $C_{d}=0.8$ and $D_{d}=1.8 \times 10^{-6}[\mathrm{~m}]$ are used as parameters in the fibre model. Similarly, eqn. 3 can be used to relate internodal distance to fibre diameters larger than $3.4 \mu \mathrm{m}$ :

$$
L=C_{L} \ln \left(\frac{D}{D_{L}}\right)
$$

$\mathrm{L}$ being internodal distance and $D$ fibre diameter; $C_{L}=$ $7.9 \times 10^{-4}$ and $D_{L}=3.4 \times 10^{-6}[\mathrm{~m}]$ are fibre model parameters. Thus, the ratios of fibre diameter to either axon diameter or internodal length are not as constant as assumed in previous models (MCNEAL, 1976; RATTAY and ABERHAM, 1993; STRUIJK et al., 1992, VELTINK et al., 1989). Eqns. 2 and 3 are applied for fibre diameters between 5 and $15 \mu \mathrm{m}$.

Next, a nodal area of $50 \mu \mathrm{m}^{2}$ was assumed to recalculate the electrical parameters per unit area. This value resulted in a membrane capacity of $0.028 \mathrm{~F} / \mathrm{m}^{2}$, which is similar to previously applied values (FRIJNS et al., 1994; SWEENEY et al., 1987). It should be considered that the ratio of membrane current and intra-axonal current is influenced by both the nodal area and the intra-axonal resistance. Because the latter was not reported by ScHWARZ et al. (1995), it was used to control the value of this ratio. After incorporating eqns. 2 and 3 , the intra-axonal resistance was set at $0.33 \Omega \mathrm{m}$ to achieve a diameter-dependent propagation velocity similar to the experimental data (SCHALOW et al., 1995; VAN VEEN et al., 1995).

Finally, a sodium equilibrium potential higher than the $39.6 \mathrm{mV}$ assumed by SCHWARZ et al. (1995) was used in the model. According to SCHOLZ et al. (1993), the sodium equilibrium potential is about $61.5 \mathrm{mV}$. SCHWARZ et al. (1995) noticed that, due to leakage resulting from membrane damage, the measured intracellular sodium concentration might be artificially high. The internal sodium concentration was reduced from $35 \mathrm{mM}$ to $30 \mathrm{mM}$, resulting in a sodium equilibrium potential of $43.7 \mathrm{mV}$.

In the current study, both simple dorsal column (DC) fibres without collaterals, and branched DC fibres with

collaterals issued anteriorly into the grey matter of the spinal cord (perpendicular to the fibre) were considered. A simple DC fibre was modelled by a McNeal type cable model with 41 compartments representing the nodes of Ranvier. As proposed by STRUIJK et al. (1992), branched DC fibres were modelled with collaterals having eight nodes attached to every second node of the main fibre. The axon and fibre diameter of a collateral were one third of the corresponding dimensions of the main fibre. The myelin sheath was supposed to be a perfect insulator although this assumption might not be entirely correct (RUBINSTEIN, 1991).

A complete description of the fibre model and its parameters is presented in the Appendix.

\subsection{Volume conductor model}

The new nerve fibre model was incorporated in a computer model used to analyse electrical stimulation of the spinal cord. Apart from the fibre model, it includes a 3D inhomogeneous volume conductor representing the spinal cord grey and (anisotropic) white matter, as well as surrounding anatomical 


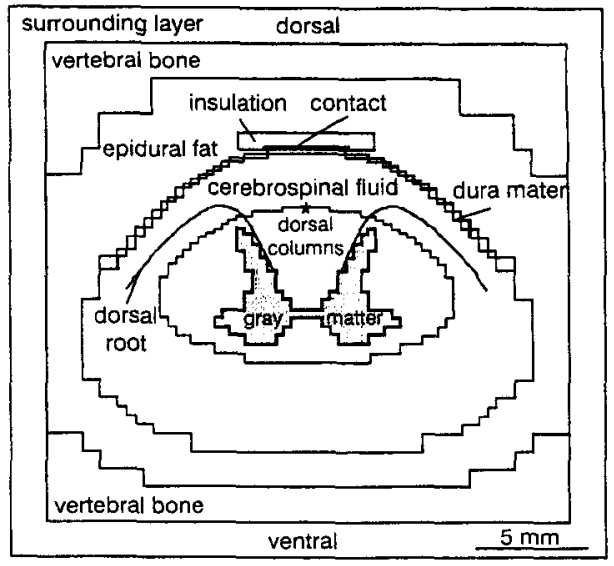

Fig. 1 Transverse section of the $3 D$ volume conductor model of the mid-cervical spinal cord

structures. A finite difference method was used to solve the potential field in the volume conductor, resulting from unipolar stimulation with an epidurally placed cathode sized $3.5 \times 3.5 \mathrm{~mm}$. Next, the potential field is applied to calculate the response of simple and branched DC fibres to stimulation with various pulses. Fig. 1 shows a transverse section of the mid-cervical 3D model used in this study, where the asterisk indicates the position of the DC fibre. The distance between the electrode and the spinal cord was $2.4 \mathrm{~mm}$. A detailed description of the SCS computer model has been published in previous work (STRUIJK et al., 1992, 1993).

\subsection{Output processing}

The amplitude and the rise and fall time characterise the shape of the AP. To determine these parameters from simulated APs, the definition proposed by FRIJNS et al. (1994) was followed. The AP was considered to be a triangle with the peak at the maximum value of the AP and the rising and falling edges crossing the AP at $10 \%$ of the peak amplitude. The duration is simply the sum of the rise time and fall time.

Chronaxie and rheobase were used to quantify strengthduration behaviour. Since SCS pulses are usually voltage controlled, activation thresholds were determined as voltages. The stimulation voltage and current have a constant ratio in the $3 \mathrm{D}$ volume conductor model, because the electrode-tissue interface is considered to be resistive. Hence, strength-duration behaviour is described by eqn. 4 , which is similar to the relation proposed by WEISS (1901):

$$
V_{t h} \tau_{p d}=V_{r h}\left(\tau_{p d}+\tau_{c h}\right)
$$

$V_{t h}$ is the threshold voltage at a certain pulse duration $\tau_{p d}, V_{r h}$ is the rheobase voltage, and $\tau_{c h}$ is the chronaxie. Threshold voltages were calculated for pulse durations ranging from 10 to $1500 \mu \mathrm{s}$. The corresponding chronaxie and rheobase were estimated by applying a linear curve fit between $V_{t,} \tau_{n d}$ and $\tau_{p d}$, since this type of linear relation provides the best fit with computed strength-duration data (BOSTOCK, 1983).

The refractory behaviour of the fibre model was characterised by the absolute and the relative refractory periods. A stimulation pulse of $100 \mu$ s duration and an amplitude $20 \%$ above the corresponding $V_{\text {th }}$ was used to elicite an initial propagating AP. A second propagating AP also resulted from stimulation with a $100 \mu$ s pulse, but with an amplitude of up to $4 V_{t h}$. The absolute refractory period is the maximum interval between the two pulses in which no second AP can be elicited, whereas the relative refractory period was defined as the maximum interval in which an elevated stimulus, i.e. larger than $101 \%$ of $V_{t h}$, was required to elicit the second propagating AP.

\section{Results}

The simulations were performed with the SCS computer model, which incorporated the complete fibre model with parameters as presented in the Appendix. Fibre diameters between 5 and $15 \mu \mathrm{m}$ were applied to characterise the model, since the largest fibres in the human dorsal columns, which are most likely to be stimulated in SCS, are within this range (WESSELINK et al., 1998). The calculated model characteristics used for validation are summarised in Table 2, which also includes the corresponding data from the fibre model we previously used for SCS modelling (SWEENEY et al., 1987). The corresponding experimentally obtained data from the literature are listed in Table 1

\subsection{Shape of the action potential}

The rise and fall times of modelled APs were calculated at $20^{\circ}$ and $25^{\circ} \mathrm{C}$ (Table 2), and compared with corresponding values estimated from experimental data (Table 1). At $20^{\circ} \mathrm{C}$, the rise and fall time of the calculated APs were $12 \%$ lower and $19 \%$ higher, respectively, whereas at $25^{\circ} \mathrm{C}$ they were both only $7 \%$ lower than their respective experimental counterparts. At $37^{\circ} \mathrm{C}$, where no experimental data were available, rise time and fall time of the calculated APs were $120 \mu \mathrm{s}$ and $470 \mu \mathrm{s}$, respectively (see also Fig. 2). The temperature dependency calculated between $20^{\circ}$ and $37^{\circ} \mathrm{C}$ corresponded to a $\mathrm{Q}_{10}$ factor of $(1.6)^{-1}$ for the rise time and $(2.5)^{-1}$ for the fall time. Calculated rise times and fall times of an AP did not change substantially when varying the fibre diameter.

The calculated AP amplitude at $37^{\circ} \mathrm{C}$ was $111 \mathrm{mV}$, whereas at $20^{\circ}$ and $25^{\circ} \mathrm{C}$ amplitudes around $117 \mathrm{mV}$ were obtained. This is similar to the experimental data of SCHWARZ and EIKHOF (1987), who concluded that the amplitude of APs decreased with increasing temperature.

Table 2 Calculated characteristics of the fibre model

\begin{tabular}{llll}
\hline Parameter & Value & Specifications & SwEENEY et al., 1987 \\
\hline Rise time $[\mu \mathrm{s}]$ & 237 & $20^{\circ} \mathrm{C}$ & \\
& 190 & $25^{\circ} \mathrm{C}$ & 63 \\
Fall time $[\mu \mathrm{s}]$ & 120 & $37^{\circ} \mathrm{C}$ & $20^{\circ} \mathrm{C}$ \\
& 2172 & $25^{\circ} \mathrm{C}$ & 262 \\
Conduction velocity/diameter $[1 / \mu \mathrm{s}]$ & 1350 & $37^{\circ} \mathrm{C}$ & 5.7 \\
Chronaxie $[\mu \mathrm{s}]$ & 470 & Fibre diam. $5-15 \mu \mathrm{m}, 37^{\circ} \mathrm{C}$ & $15-20$ \\
ARP $[\mathrm{ms}]$ & $3.1-4.3$ & Fibre diam. $5-15 \mu \mathrm{m}, 37^{\circ} \mathrm{C}$ & 0.37 \\
\hline
\end{tabular}




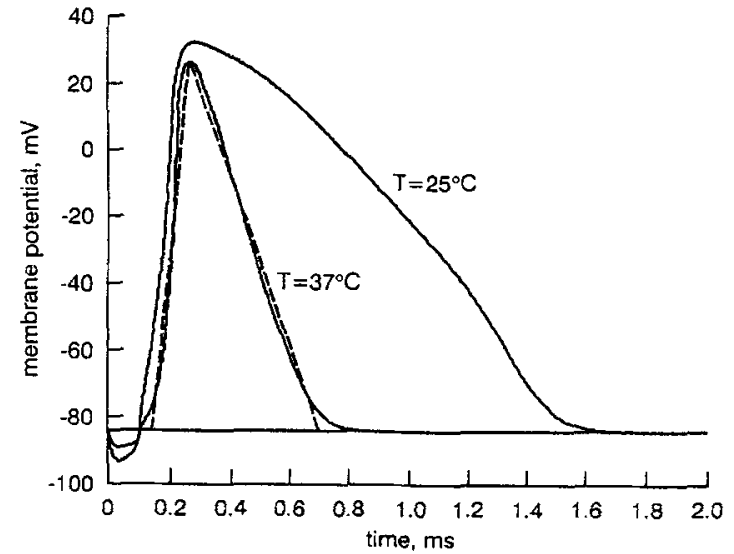

Fig. 2 Simulated propagating action potentials at 25 and $37^{\circ} \mathrm{C}$ (new model); (-..) rise time and fall time of the action potential at $37^{\circ} \mathrm{C}$

\subsection{Conduction velocity}

The simple DC fibre model exhibited a diameter dependency of AP conduction velocity, which is shown in Fig. 3 at a temperature of $37^{\circ} \mathrm{C}$. Also shown are experimental data (SCHALOW et al., 1995; VAN VEEN et al., 1995), and calculated data using our previous DC fibre model. For smaller fibres, the new model fits the Schalow data less well than the data of Van Veen, who, however, presented only two experimental data points $(3.1$ and $8.4 \mu \mathrm{m})$.

The relation between conduction velocity $v[\mathrm{~m} / \mathrm{s}]$ and fibre diameter $D[\mu \mathrm{m}]$ was almost linear and fitted $v=C_{c} D-v_{D}$, with $v_{D}=9.0 \mathrm{~m} / \mathrm{s}$, and $C_{r}=4.9 \times 10^{6}$. The value of $v_{D}$ resulted from fitting the model to the experimental data. The ratio $v / D$ thus ranged from $3.1 \times 10^{6}$ for $D=5 \mu \mathrm{m}$ to $4.3 \times 10^{6}$ for $D=15 \mu \mathrm{m}$, in contrast with the previous model, where this ratio was constant at $5.7 \times 10^{6}$. The temperature dependency of conduction velocity at temperatures between $20^{\circ}$ and $37^{\circ} \mathrm{C}$ corresponded to a $\mathrm{Q}_{10}$ factor of 1.3 .

\subsection{Strength-duration behaviour}

The strength-duration curves of simple and branched fibres with diameters ranging from 5 to $15 \mu \mathrm{m}$ were calculated for pulses of $10-1500 \mu$ s duration. An example is presented in Fig. 4 , where the strength-duration curve of a $5 \mu \mathrm{m}$ branched fibre

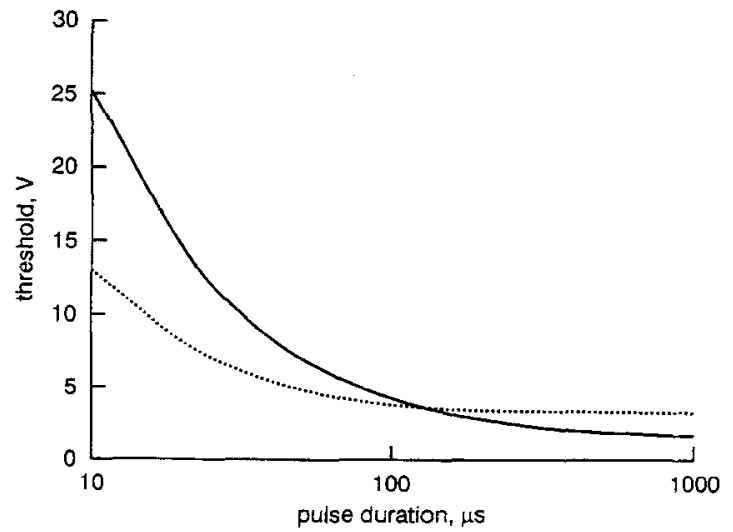

Fig. 4 Strength-duration curves of a branched $5 \mu \mathrm{m}$ fibre using the new model ( - ) and the previous model ( ) ) lines cross at $\sim 113 \mu s$

calculated using the new and the previous fibre model are shown. The rheobase voltage of simple fibres decreased by $82 \%$ when the diameter was increased from 5 to $15 \mu \mathrm{m}$. This reduction was $74 \%$ for branched fibres. The difference between the rheobase of both fibre types decreased from 45 to $10 \%$ with increasing diameter.

Fig. 5 shows the calculated chronaxie values of the branched and simple new fibre models, and the previous simple fibre model, the latter being up to $90 \%$ smaller. Chronaxie values of simple fibres decreased from 202 to $126 \mu$ s with diameters increasing from 5 to $15 \mu \mathrm{m}$. Branched fibres showed a similar behaviour with a chronaxie reduction from 167 to $113 \mu \mathrm{s}$. In contrast to the previous model, chronaxie is markedly dependent on fibre diameter, reducing by $37 \%$ and $32 \%$ for simple and branched fibres, respectively.

\subsection{Refractory period}

The calculated absolute refractory period of a $10 \mu \mathrm{m}$ simple fibre model was $1.0 \mathrm{~ms}$. The relative refractory period was about $3.1 \mathrm{~ms}$. After this time, an amplitude only $1 \%$ above the original threshold amplitude was enough to elicit a second propagating AP. The relative refractory period and the absolute refractory period of fibres with other diameters had similar values, implying that these parameters of the fibre model are virtually diameter independent.

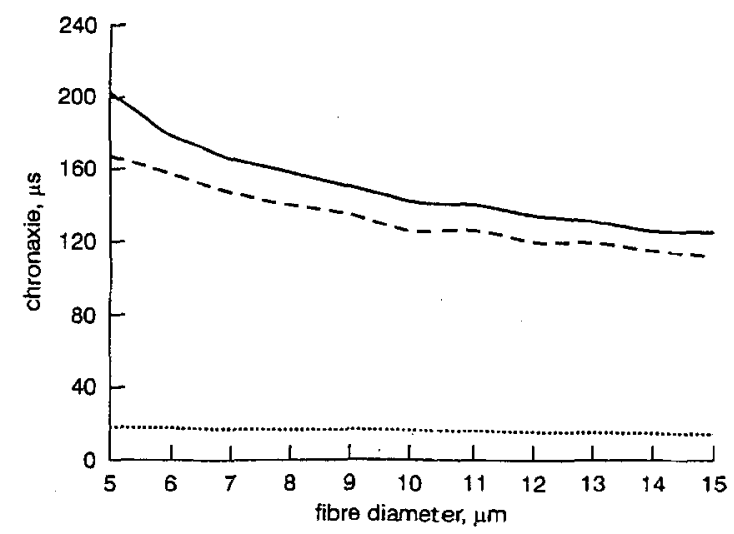

Fig. 5 Chronaxie against diameter using the simple fibre model (-), the branched fibre model ( - . -) and the previous model $(\longrightarrow)$ 


\subsection{Influence of collateral branching on fibre characteristics}

The target fibres in SCS (dorsal column fibres) have collaterals, which clearly influence the fibre characteristics. When a fibre model had collaterals attached to each second node, the APs in the main fibre were $2 \mathrm{mV}$ smaller in amplitude and were propagated at an $8-19 \%$ lower velocity than with simple fibre models. The most important difference, however, is that threshold stimuli for branched fibre models were 8 to $52 \%$ lower than for simple fibre models (pulse duration $10-1500 \mu \mathrm{s}$ ). The largest differences were found for the smallest fibres, i.e. 5-6 $\mu \mathrm{m}$ diameter. Chronaxie values were $9-19 \%$ less in branched fibres, where the largest difference was found for the smallest diameter fibres (Fig. 5).

\section{Discussion}

This paper presents a new fibre model to describe the electrical behaviour of human myelinated sensory nerve fibres. The model was based on the membrane kinetics of human sensory nerve fibres (SCHWARZ et al., 1995) and on the morphometry of human AII fibres (BEHSE, 1990). We compared this model only with the fibre model we previously used for SCS modelling, since the mammalian fibre models available to date have already been compared extensively by other authors (FRIJNS et al., 1994; FRIJNS and TEN KATE, 1994; RATTAY and ABERHAM, 1993). These studies showed that the choice of specific fibre model depends on the type of neural substrate to be analysed.

\subsection{Parameters of the fibre model}

The shape of the AP at $37^{\circ} \mathrm{C}$ was not known exactly, but at lower temperatures amplitude, rise time and fall time corresponded well with the values measured by SCHWARZ et al. (1995). At $20^{\circ}$ and $25^{\circ} \mathrm{C}$, the differences between calculated and experimental values of rise times and fall times were $19 \%$ or less. The remaining differences are most probably related to the larger modelled sodium equilibrium potential, resulting in a somewhat faster change of membrane potential during an AP.

PAINTAL (1966) showed a diameter dependency of rise and fall time in cats. The fact that our model does not show this dependency to a significant degree could be either a shortcoming of the model or a difference between human and cat nerve fibres. Compared to other mammalian nerve fibre models (FRIJNS et al., 1994; SWEENEY et al., 1987), rise and fall times at $37^{\circ} \mathrm{C}$ were up to twice as long, whereas the corresponding $\mathrm{Q}_{10}$ factors were up to $35 \%$ smaller. These models, however, were not based on human nerve fibre parameters.

The modelled conduction velocities correspond better with experimental data from human sensory nerve fibres than the results from our previous model did. The conduction velocity of a propagating AP along a human sensory nerve fibre seems to be less than has previously been assumed. Although we calculated an almost linear relation between fibre diameter and conduction velocity, the ratio $v / D$ is not constant. It should be noticed that for fibres smaller than $5 \mu \mathrm{m}$ and larger than $15 \mu \mathrm{m}$ the relation between diameter and propagation velocity might differ from the one presented in this paper. It is well known that conduction velocity depends on temperature, although the exact relation for this fibre type is unknown. The model predicts that propagation velocity is related to temperature by a $Q_{10}$ factor of 1.3 , which is just below the range of 1.4-1.6 determined from experiments on cats (PAINTAL, 1978) and calculated with previous mathematical models (FRIJNS et al., 1994; SWEENEY et al., 1987).

Strength-duration behaviour of the new model showed, besides the expected diameter-related threshold voltages, a clear diameter dependency of the chronaxie. Its values calculated for branched and simple fibres ranged from 113 to $202 \mu \mathrm{s}$, and were inversely related to fibre diameter, as was observed in experiments (JANKOWSKA and ROBERTS, 1972; NOWAK and BULLIER, 1998; WEST and WOLSTENCROFT, 1983). Moreover, it was calculated that the chronaxie increased by $20 \%$ when the SCS electrode-fibre distance was increased from 1 to $5 \mathrm{~mm}$. The rather wide range of experimental human data may be caused by the diverse stimulation conditions and the different methods used to determine the chronaxie. If a comparison is made with the data resulting from microneurographic recordings from human peripheral nerves (PANIZZA et al., 1998), taking into account a $9 \%$ decrease due to the method of latent addition (resulting chronaxie $336 \mu \mathrm{s}$ ), our chronaxie values are about $40 \%$ less. However, the applied surface stimulation may result in an overestimation of chronaxie values. Nonetheless, the chronaxie values calculated with the new model are substantially closer to experimental data than those from previous mammalian fibre models. The clear dependency on fibre diameter and the range of chronaxie values found could explain why patients undergoing SCS may perceive a wider paraesthesia coverage when the duration of the stimulating pulses is increased to $1500 \mu \mathrm{s}$ (BURTON, 1975). Most probably, a larger number of smaller DC fibres inducing paraesthesia is activated in the dorsal columns by long pulses, because the difference in threshold voltage between these fibres and the largest DC fibres is less than for shorter pulses.

The absolute refractory period was calculated at $1.0 \mathrm{~ms}$, which is still slightly longer than the range of experimental human data, $0.58-0.79 \mathrm{~ms}$. The calculated relative refractory period of $3.1 \mathrm{~ms}$ agrees well with the measured value of $3.0 \mathrm{~ms}$ (GILLIAT and WILSON, 1963). The ratio of the absolute refractory period and the relative refractory period, at 3.1 , is slightly below reported experimental values of 3.5-5 (TACKMANN and LEHMANN, 1974). The ratio of the absolute refractory period and the duration of the propagating AP of the new fibre model was 1.7. Although the absolute refractory period was about twice as long as determined in cats, its proportionality to the AP duration agreed well (PAINTAL, 1973). The results show that the behaviour of the new model for human myelinated sensory nerve fibres corresponds substantially better with the properties measured for this type of human nerve fibre than our previous fibre model did.

\subsection{Implications for SCS modelling}

Since the output of the SCS computer model is mainly in terms of threshold voltages, the implications of applying the new fibre model for SCS modelling work are primarily related to its strength-duration behaviour. The previous fibre model we used (SWEENEY et al., 1987) was based on experimental data for rabbit nerve fibres (CHIU et al., 1979). The strengthduration behaviour of the new model differs from the previous fibre model in two aspects: the chronaxie values are up to 10 times higher and show a large decrease with increasing fibre diameter. Additionally, the new model expresses increased stimulation thresholds at short pulse durations, whereas for long pulses the thresholds are reduced compared to the previous model. The difference is shown in Fig. 4 for a $5 \mu \mathrm{m}$ branched DC fibre. The strength-duration curves for fibres between 5 and $15 \mu \mathrm{m}$ in both models cross between 50 and $200 \mu \mathrm{s}$. At the rheobase, the activation thresholds predicted by the new model are $115-175 \%$ lower. 


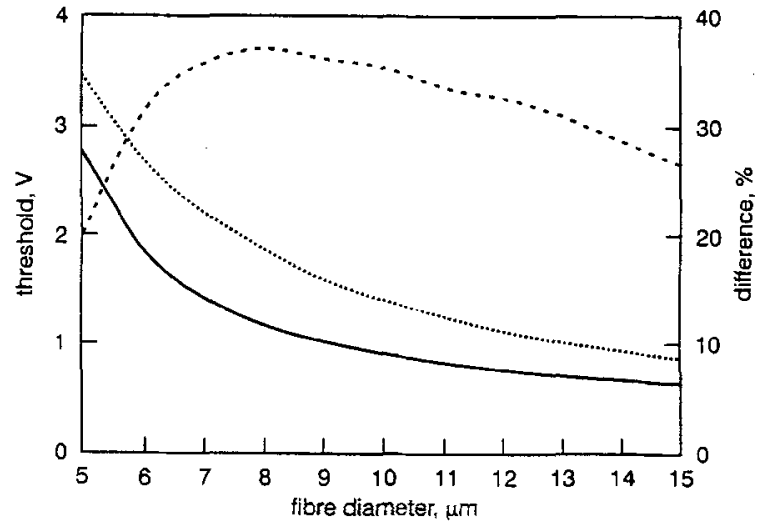

Fig. 6 Threshold stimuli of branched DC fibres at a pulse duration of $210 \mu \mathrm{s}$ using the new model (-) and the previous model ( ); percentage difference (- . -)

The new model allows better prediction of the threshold voltages in SCS. Values calculated by both fibre models were compared at a pulse duration of $210 \mu$ s, as is usual in SCS. As shown in Fig, 6, the new model predicts $20-37 \%$ lower thresholds at this specific pulse duration. The larger values obtained with the previous model may explain in part the results of a validation study of the SCS computer model with clinical data (STRUIJK et al., 1993), showing that the predicted threshold voltages were $2.5-3$ times too high.

Acknowledgment-The authors gratefully thank Medtronic Inc. (Minneapolis, MN) for their grant to support this research.

\section{Appendix}

The fibre model and its parameters at $37^{\circ} \mathrm{C}$

\section{Fibre geometry}

$d \quad$ axon diameter $[\mathrm{m}]$

$D$ fibre diameter $[\mathrm{m}]$

$L \quad$ internodal length $[\mathrm{m}]$

$l$ nodal width, $1.5 \mu \mathrm{m}$

$\pi d l$ nodal area $\left[\mathrm{m}^{2}\right]$

$d=C_{d} D-D_{d}, C_{d}=0.76, D_{d}=1.81 \times 10^{-6}$

$L=C_{L} \ln \left(D / D_{L}\right), C_{L}=7.87 \times 10^{-6}, D_{L}=3.44 \times 10^{-6}$

\section{Gating variables}

$a_{m}=4.6 \times 10^{3}(V+18.4) /\left(1-e^{(-18.4-V) / 10.3}\right)$

$b_{m}=0.33 \times 10^{3}(-22.7-V) /\left(1-e^{(V+22.7) / 9.16}\right)$

$a_{h}=0.21 \times 10^{3}(-111-V) /\left(1-e^{(V+111) / 11}\right)$

$b_{h}=14.1 \times 10^{3} /\left(1+e^{(-28.8-V) / 1.1}\right)$

$a_{n}=51.7(V+93.2) /\left(1-e^{(-93.2-V) / 1.1}\right)$

$b_{n}=92(-76-V) /\left(1-e^{(V+76) / 10.5}\right)$

gating coefficients $a, b$ in $\mathrm{ms}^{-1}$

$d m / d t=a_{m}(1-m)-b_{m} m$

$d h / d t=a_{h}(1-h)-b_{h} h$

$d n / d t=a_{n}(1-n)-b_{n} n$

$m(0)=0.0382$

$h(0)=0.6986$

$n(0)=0.2563$

membrane potential $V$ in millivolts $(\mathrm{mV})$

\section{Parameters}

$c_{m}$ membrane capacity, $0.028 \mathrm{~F} / \mathrm{m}^{2}$

$g_{L}$ leakage conductance, $600 \mathrm{~S} / \mathrm{m}^{2}$

$p_{N a}$ sodium permeability, $0.0704 \mathrm{dm}^{3} / \mathrm{m}_{2} \mathrm{~s}$

$g_{K}$ potassium conductance, $300 \mathrm{~S} / \mathrm{m}^{2}$

$\rho_{a}$ intra-axonal resistance, $0.33 \Omega \mathrm{m}$

$V_{L} \quad$ leakage equilibrium potential, $-84.14 \mathrm{mV}$
$V_{N a}$ sodium equilibrium potential, $43.7 \mathrm{mV}$

$\mathrm{Na}_{o}$ sodium concentration outside cell, $154 \mathrm{mM}$

$\mathrm{Na}$, sodium concentration inside cell, $30 \mathrm{~mm}$

$V_{K}$ potassium equilibrium potential, $-84 \mathrm{mV}$

$V_{r}$ resting membrane potential, $-84 \mathrm{mV}$

$F \quad$ Faraday constant, $96485 \mathrm{C} /$ mole

$R$ gas constant, $8.3144 \mathrm{~J} / \mathrm{K}$ mole

$T$ absolute temperature, $310.15 \mathrm{~K}$

\section{Membrane currents}

$i_{N a}$ sodium current $\left[\mathrm{A} / \mathrm{m}^{2}\right]$

$i_{K}$ (fast) potassium current $\left[\mathrm{A} / \mathrm{m}^{2}\right]$

$i_{L}$ leakage current $\left[\mathrm{A} / \mathrm{m}^{2}\right]$

$i_{i o n}$ total ionic current $\left[\mathrm{A} / \mathrm{m}^{2}\right]$

$i_{c} \quad$ capacitive current $\left[\mathrm{A} / \mathrm{m}^{2}\right]$

$I_{m e m}$ total nodal membrane current [A]

$i_{N a}=m^{3} h p_{N a} V F^{2} / R T\left(N a_{o}-N a_{i} \mathrm{e}^{V F / R T}\right) /\left(1-e^{V F / R T}\right)$

$i_{K}=n^{4} g_{K}\left(V-V_{K}\right)$

$i_{L}=g_{L}\left(V-V_{L}\right)$

$i_{\text {ion }}=i_{N a}+i_{K}+i_{L}$

$i_{c}=c_{m} d V / d t$

$I_{\text {mem }}=\left(i_{\text {ion }}+i_{c}\right) \pi d l$

\section{References}

BEHSE, F. (1990): 'Morphometric studies on the human sural nerve', Acta Neurol. Scand., 82, Suppl. 132, pp. 1-38

BEMENT, S. L., and RANCK, J. B. (1969): 'A quantitative study of electrical stimulation of central myelinated fibers with monopolar electrodes', Exp. Neurol., 24, pp. 147-170

BOSTOCK, H. (1983): 'The strength-duration relationships for excitation of myelinated nerve: computed dependence on membrane parameters', J. Physiol., 341, pp. 59-74

BostoCK, H., and RoTHWELL, J. C. (1997): 'Latent addition in motor and sensory fibres of human peripheral nerve' J. Physiol. (London), 498, pp. 227-294

BOYD, I. A., and KALU, K. U. (1979): 'Scaling factor relating conduction velocity and diameter for myelinated afferent nerve fibres in the cat hind limb', J. Physiol., 289, pp. 277-297

BUCHTHAL, F., and RosenfaLCK, A. (1966): 'Evoked action potentials and conduction velocity in human sensory nerves', Brain Res., 3 (special issue)

BURTON, C. (1975): 'Dorsal column stimulation: optimization of application', Surg. Neurol., 4, pp. 171-176

ChIU, S. Y., RITCHIE, J. M., ROGART, R. B., and STAGG, D. (1979): 'A quantitative description of membrane currents in rabbit myelinated nerve', $J$. Physiol., 292, pp. 149-166

Frankenhaeuser, B., and HuXley, A. F. (1964): 'The action potential in the myelinated nerve fibre of Xenopus Leavis as computed on the basis of voltage clamp data', J. Physiol., 171, pp. 302-315

FRIJNS, J. H., MOOIJ, J., and TEN KATE, J. H. (1994): 'A quantitative approach to modeling mammalian myelinated nerve fibers for electrical prosthesis design', IEEE Trans. Biomed. Eng., 41, pp. $556-566$

FRIJNS, J. H. M., and TEN KATE, J. H. (1994): 'A model of myelinated nerve fibres for electrical prosthesis design', Med. Biol. Eng. Comput., 32(4), pp. 391-398

GILLIAT, R. W., and WILSON, R. G. (1963): 'The refractory and supernormal periods of the human median nerve', J. Neurol. Neurosurg. Psychiat., 26, pp. 136-147

HODGKIN, A. L., and HUXLEY, A. F. (1952): 'A quantitative description of membrane currents and its application to conduction and excitation in nerve', J. Physiol., 117, pp. 500-544

Ishikawa, M., OHIRA, T., Yamaguchi, N., TAKase, M., BertaLANFFY, H., KAWASE, T., and TOYA, S. (1996): 'Strength-duration of conductive spinal cord evoked potentials in cats', Electroenceph. Clin. Neztrophysiol., 100, pp. 261-268

JANKOWSKA, E., and ROBERTS, W. J. (1972): 'An electrophysiological demonstration of the axonal projections of single spinal interneurons in the cat', J. Physiol., 222, pp. 597-622, 
MCNEAL, D. R. (1976): 'Analysis of a model for excitation of myelinated nerve', IEEE Trans. Biomed. Eng., 23, pp. 329-337

Mogyros, I., Kiernan, M. C., and BurKe, D. (1996): 'Strengthduration properties of human peripheral nerve', Brain, 119, pp. 439-447

NOWAK, L. G., and Bullier, J. (1998): 'Axons, but not cell bodies, are activated by electrical stimulation in cortical gray matter: I. Evidence from chronaxie measurements', Exp. Brain Res., 118, pp. $477-488$

PAINTAL, A. S. (1966): 'The influence of diameter of medullated nerve fibers of cat on the rising and falling phases of the spike and its recovery', J. Physiol., 184, pp. 79l-811

PAINTAL, A. S. (1973): 'Conduction in mammalian nerve fibres', in DESMEDT, J. E. (Ed.): 'New developments in electromyography and clinical neurophysiology' (Karger, Basel), pp. 19-41

PAINTAL, A. S. (1978): "Conduction properties of normal peripheral mammalian axons', in WAXMAN, S. G. (Ed.): 'Physiology and pathobiology of axons' (Raven Press, New York) pp. $131-144$

Panizza, M., Nilsson, J., Roth, B. J., Rothwell, J. and Hallett, M. (1994): 'The time constants of motor and sensory peripheral nerve fibers measured with the method of latent addition', Electroenceph. Clin. Neurophysiol., 93, pp. 147-154

Panizza, M., Nilsson, J., Roth, B. J., Grill, S. E., Demirci, M., and HALLET, M. (1998): 'Differences between the time constant of sensory and motor peripheral nerve fibers: further studies and considerations', Muscle \& Nerve, 21, pp. 48-54

RATTAY, F., and ABERHAM, M. (1993): 'Modeling axon membranes for functional electrical stimulation', IEEE Trans. Biomed. Eng., 40, pp. $1201-1209$

RUBinSTEIN, J. T. (1991): 'Analytical theory for extracellular electrical stimulation of nerve with focal electrodes: II. Passive myelinated axon', Biophys. J., 60, pp. 538-555

SCHALOW, G., ZÄCH, G. A., and WARZOK, R. (1995): 'Classification of human peripheral nerve fiber groups by conduction velocity and nerve fiber diameter is preserved following spinal cord lesion', J. Aut. Nervous Syst., 52, pp. 125-150

SChOlz, A., Reid, G., Vogel, W., and Bostock, H. (1993): 'Ion channels in human axons', J. Neurophysiol., 70, pp. 1274-1279

SCHWARZ, J. R., and EIKHOF, G. (1987): 'Na-currents and action potentials in rat myelinated nerve fibers at 20 and $37^{\circ} \mathrm{C}$ ', Pflugers Arch., 409, pp. 569-577

Schwarz, J. R., Reid, G., and Bostock, H. (1995): 'Action potentials and membrane currents in the human node of Ranvier', Eur. J. Physiol., 430, pp. 283-292
Struijk, J. J., Holsheimer, J., Van Der Heide, G. G., and Boom, H. B. K. (1992): 'Recruitment of dorsal column fibers in spinal cord stimulation: Influence of collateral branching', IEEE Trans. Biomed. Eng., 39, pp. 903-912

Struijk, J. J., Holsheimer, J., Barolat, G., He, J., and BoOM, H. B. K. (1993): 'Paresthesia thresholds in spinal cord stimulation: A comparison of theoretical results with clinical data', IEEE Trans. Rehab. Eng., 1, pp. 101-108

SWEeneY, J. D., MORTIMER, J. T., and Durand, D. (1987): 'Modeling of mammalian myelinated nerve for functional neuromuscular stimulation', Proc. IEEE 9th Conf. of the EMBS, pp. 1577-1578

TACKMANN, W., and LEHMANN, H. J. (1974): 'Refractory period in human sensory nerve fibers', Eur. Neurol., 12, pp. 277-292

Van Veen, B. K., Schellens, R. L. L. A., Stegeman, D. F., SCHOONHOVEN, R., and GABREËLS-FESTEN, A. A. W. M. (1995): 'Conduction velocity distributions in normal human sural nerve', Muscle \& Nerve, 18, pp. 1121-1127

Veltink, P. H., VAn VeEn, B. K., Struijk, J. J., Holsheimer, J., and BoOM, H. B. K. (1989): 'A modeling study of nerve fascicle stimulation', IEEE Trans. Biomed. Eng., 36, pp. 683-692

WEISS, G. (1901): 'Sur la possibilité de rendre comparables entre eux les appareils servant à l'excitation électrique', Arch. Ital. de Biol., 35, pp. 413-446

Wesselink, W. A., Holsheimer, J., Nuttin, B., BoOM, H. B. K., KinG, G. W., GyBels, J. M., and DE SUTTER, P. (1998): 'Estimation of fiber diameters in the spinal dorsal columns from clinical data', IEEE Trans. Biomed. Eng. (in press)

WEST, D. C., and WOLSTENCROFT, J. H. (1983): 'Strength-duration characteristics of myelinated and non-myelinated bulbospinal axons in the cat spinal cord', J. Physiol., 337, pp. 37-50

\section{Author's biography}

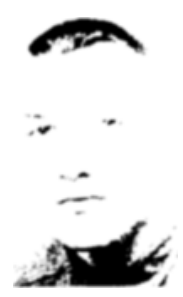

WILBERT WESSELINK was born in Zelhem. The Netherlands, in 1970. In 1994 he received an MSc degree in Electrical and Biomedical Engineering from the University of Twente, The Netherlands. He joined the Institute for Biomedical Technology in 1994 as a PhD student. His research is on computer modelling of spinal cord stimulation, and the evaluation of clinical studies in which new electrode configurations are applied. 